Seminar Nasional Teknologi Informasi dan Kedirgantaraan (SENATIK)

Vol. II, 26 November 2016, ISSN: 2528-1666

\title{
PENGUJIAN KINERJA JARINGAN SISTEM AKSES FILE BERBASIS CLIENT SERVER MENGGUNAKAN SAMBA SERVER
}

\author{
Anggraini Kusumaningrum \\ Program Studi Teknik Informatika \\ Sekolah Tinggi Teknologi Adisutjipto \\ Jl. Janti Blok R Lanud Adisutjipto, Yogyakarta 55198 \\ anggraini@stta.ac.id
}

\begin{abstract}
Data communication is the process of exchanging data between two or more devices through a transmission medium such as a cable. In order for the data communication can occur, the device must be connected to communicate with each other or be a part of a communication system consisting of hardware (hardware) and software (software). Samba server is a software bridge between the two operating systems that run within a computer network. Samba is able to share files with computers that use operating system linux, unix and windows with a peer to peer system. The time needed on the LAN network access system based on client file servers using Samba server with a minimum file size of $3 M B$ and a maximum of $1 G B$ for the download process is 04 minutes 54 seconds while the upload is 09 minutes 24 seconds. Speed transfer rate that is produced with a minimum file size of $3 \mathrm{MB}$ and a maximum of $1 \mathrm{~GB}$ for the download process is $4.762 \mathrm{Kbps}$ and to upload is $1.896 \mathrm{Kbps}$. On QoS testing conducted on 5 PCs, 10PC, 15pc and client 20PC result more and more PC client that accesses 1 file the success rate will be getting worse, it is because the bottleneck on the network.
\end{abstract}

Key Words : Network, client server, Samba Server

\section{Pendahuluan}

Perkembangan teknologi saat ini semakin vital perannya dalam kegiatan pendistribusian informasi, pendistribusian informasi yang cepat sangat membantu kebutuhan manusia akan komunikasi dan informasi. Berbicara tentang teknologi informasi tentunya tidak terlepas dari sistem operasi dan teknologi jaringan komputer. Selain kemudahan komunikasi, jaringan juga memudahkan pengguna dengan beragam aplikasinya melalui sistem operasi open source seperti samba server, mail server, web server dan lain-lain. Kebutuhan tempat penyimpanan data yang besar dan dapat diakses dari mana saja untuk kepentingan perkuliahan dan praktikum semakin tahun semakin dirasakan.

Dalam pelaksanaan praktikum yang menggunakan komputer sebagai perangkat praktikum, penggunaan file sharing sangat bermanfaat, hal ini disebabkan file hasil praktikum mulai dari praktikum pertama hingga praktikum terakhir ternyata saling berkesinambungan, sehingga mahasiswa dituntut untuk menggunakan komputer yang sama setiap praktikumnya. Dalam pelaksanaannya ternyata hal tersebut cukup sulit untuk dilaksanakan, dan hal tersrbut menjadi alasan bagi praktikan untuk menunda mengerjaan praktik nya.

Berdasarkan hal tersebut penelitian ini dimaksudkan untuk membuat sistem file sharing berbasis client server dengan menggunakan samba server.

Penerapan sistem samba server menggunakan Ubuntu 8.04 di SMA swasta Insani Binjai. Samba software tersebut digunakan sebagai jembatan sistem jaringan dengan sistem operasi yang berbeda antara Windows dan Linux [1]. Penerapan file server menggunakan samba dan LDAP di U'Budiyah Indonesia yang mampu menangani permasalahan dalam hal kurangnya pemanfaatan menajemen file terpusat [2]. Web server untuk intranet merupakan salah satu solusi yang bias digunakan bagi daerahdaerah yang belum terjaman dengan internet. Web 
server tersebut digabungkan dengan Linux Terminal Service Project (LTSP) [3].

\section{Metode Penelitian}

\subsection{Jaringan komputer}

Jaringan komputer adalah sebuah kumpulan komputer, printer dan peralatan lainnya yang terhubung dalam satu kesatuan [4]. Informasi dan data bergerak melalui kabel-kabel atau tanpa kabel sehingga memungkinkan pengguna jaringan komputer dapat saling bertukar dokumen dan data, mencetak pada printer yang sama dan bersama-sama menggunakan hardware/software yang terhubung dengan jaringan.

\subsection{Client Server}

Sistem jaringan client server memungkinkan adanya fungsi dan aplikasi terpusat pada satu atau lebih file server. File server menjadi jantung sistem jaringan, menyediakan akses file, beserta sistem keamanannya. Komputer client bis a mengakses data di server [5].

\subsection{Samba Server}

Samba merupakan implementasi dari protokol SMB (Server Message Block) pada sistem UNIX. Protokol ini digunakan MS Windows NT untuk file dan Printing Sharing Service. Dengan mengaktifkan samba pada mesin Linux, maka suatu jaringan komputer dapat berbagi file dan printer dengan Windows 95/98 atau pun Windows NT. Dengan kata lain, dengan menjalankan samba maka server Linux dapat tampak seperti Windows NT Server bagi mesin Windows lainnya. Pada Linux dapat me-mounting direktori yang di-share pada Windows dan juga dapat mengakses secara langsung direktori tersebut. Sedangkan pada Windows, juga dapat melihat direktori yang di-share berupa icon yang terdapat dalam Network Neighborhood [6].

\subsection{Perancangan Sistem}

\subsubsection{Skema Jaringan}

Pada implementasi sistem akses file berbasis client server dengan menggunakan samba server ini berjalan di Local Area Network (LAN). Gambar 1 merupakan skema jaringan LAN pada sistem akses file berbasis client server menggunakan samba server.

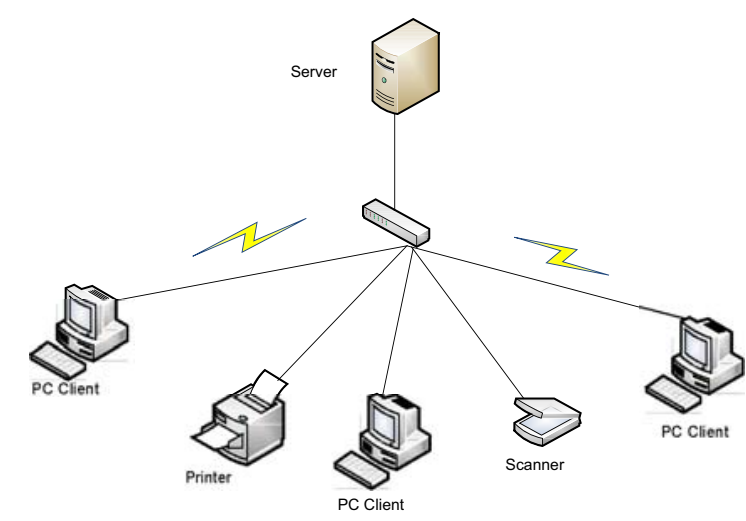

Gambar 1. Skema jaringan

Pada Gambar 1 server dikoneksikan dengan sebuah switch dengan network yang sama. File Server adalah sebuah komputer terpasang ke jaringan yang memiliki tujuan utama memberikan lokasi untuk akses disk bersama, dalam kasus ini server bertindak sebagai router dan file server yang dapat diakses oleh PC client dan PC client dapat mengakses printer dan scanner bersama.

\subsubsection{Deployment Diagram}

Di dalam deployment diagram ini menunjukkan konfigurasi komponen dalam proses eksekusi penyimpanan data. Aplikasi ini dijalankan dengan perangkat komputer yang terhubung dengan server samba yang berfungsi untuk sharing data. Gambar 2 merupakan deployment diagram.

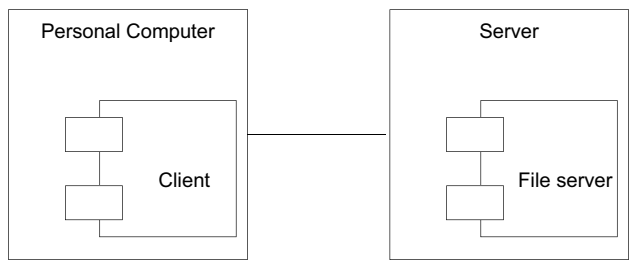

Gambar 2. Deployment Diagram

Pada Gambar 2 PC client akan langsung berhubungan dengan server yang bertindak sebagai router dan file server. Disisi client dapat menggunakan system operasi windows atau linux, sedangkan di sisi server akan menggunakan system operasi linux.

\subsubsection{Flowchart Sistem}

Flowchart sistem menggambarkan alur dari sistem yang berjalan. Gambar 3 merupakan 
flowchart sistem akses file berbasis client server dengan menggunakan samba server.

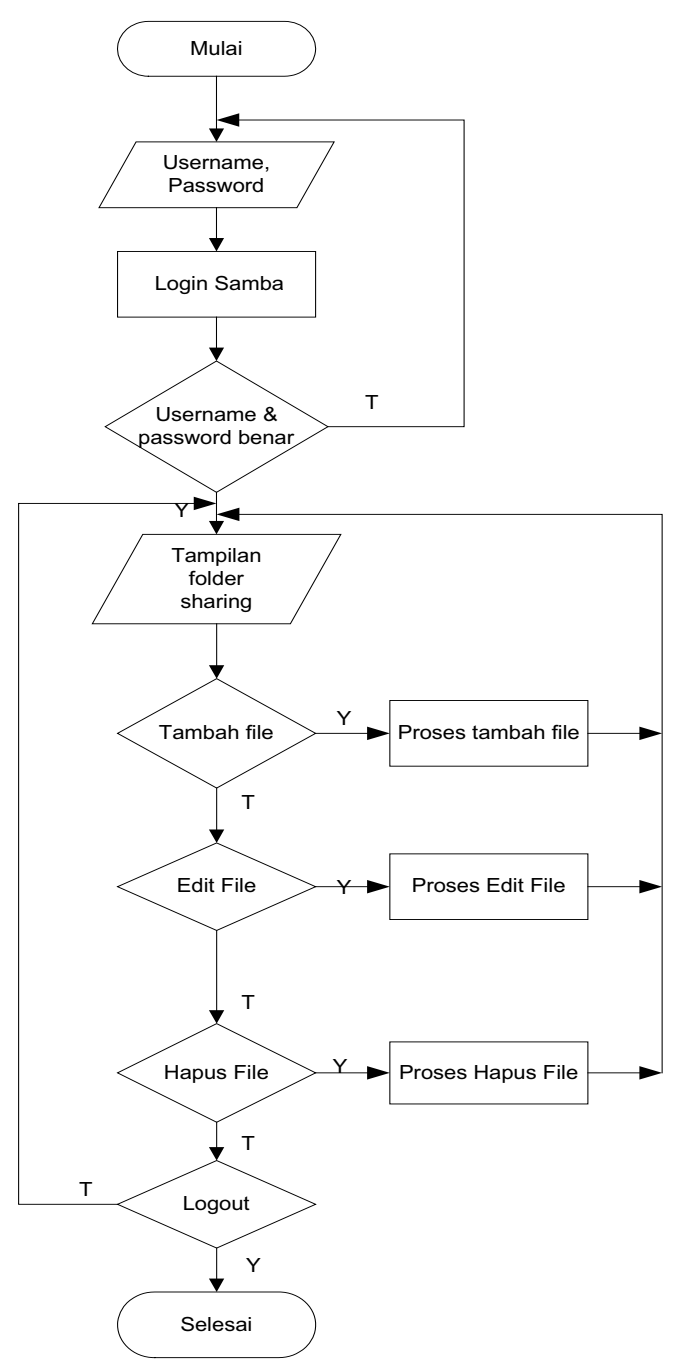

Gambar 3. Flowchart Sistem

Pada Gambar 3 user akan diminta memasukkan user name dan password terlebih dahulu untuk login. Jika berhasil login, user akan diarahkan ke halaman folder sharing, di dalam folder sharing user dapat melalukan tambah, edit dan hapus file. Jika user tidak berhasil login, maka akan diminta memasukkan user name dan password kembali.

\subsubsection{Tahapan Konfigurasi Server}

Tahapan konfigurasi server merupakan tahapan yang dilakukan di sisi server. Beberapa tahapan yang dilakukan untuk konfigurasi server adalah sebagai berikut:

1. Pengaturan pembagia IP address. Pada penelitian ini digunakan IP kelas $\mathrm{C}$ dengan pengaturan aomatis atau DHCP untuk menghindari IP yang sama.

2. Instalasi server. Pada penelitian ini digunakan sistem operasi Ubuntu 11.10 server.

3. Instalasi samba server. Samba server digunakan untuk menghubungkan antara client dengan sistem operasi Windows dan server dengan sistem operasi Linux.

4. Konfigurasi samba. Pada tahapan konfigurasi samba ini dilakukan konfigurasi untuk user, hak akses user dan file sharing.

5. Konfigurasi komputer client. Pada tahapan ini dilakukan konfigurasi agar dapat mengakses file sharing yang terdapat di server.

\section{Hasil dan Pembahasan}

\subsection{Pengujian Kinerja Jaringan}

Pada pengujian kinerja jaringan ini akan dilakukan pengujian pengiriman dan penerimaan data memanfaatkan koneksi kabel LAN. Pengujian download dan upload melalui kabel LAN

\subsubsection{Berdasarkan Waktu}

Pada penelitian ini adalah hasil pengukuran dengan stopwatch digunakan untuk menghitung waktu yang diperlukan mengirim data yang telah ditentukan. Tabel 1 dengan uji coba 1 client dengan besar kapasitas file yang telah di tentukan. 
Tabel 1. Data Pengujian Waktu dengan LAN

\begin{tabular}{|c|c|c|c|c|}
\hline \multirow[b]{2}{*}{ No } & \multirow[b]{2}{*}{ Nama File } & \multirow[b]{2}{*}{$\begin{array}{l}\text { Ukuran } \\
\text { File }\end{array}$} & \multicolumn{2}{|c|}{ Waktu (s) } \\
\hline & & & \begin{tabular}{|c|}
$\begin{array}{c}\text { Down- } \\
\text { load }\end{array}$ \\
\end{tabular} & $\begin{array}{l}\text { Up- } \\
\text { load }\end{array}$ \\
\hline 1 & Foto.jpg & $3 \mathrm{MB}$ & 3.5 & 4.2 \\
\hline 2 & $\mathrm{Mp} 3$ & $4 \mathrm{MB}$ & 5.3 & 5.1 \\
\hline 3 & PDF & $5 \mathrm{MB}$ & 5.9 & 7.0 \\
\hline 4 & Word & $10 \mathrm{MB}$ & 6.1 & 12.9 \\
\hline 5 & MiPhoneflash.exe & $20 \mathrm{MB}$ & 7.4 & 14.1 \\
\hline 6 & MiSetup2.exe & $30 \mathrm{MB}$ & 8.6 & 14.9 \\
\hline 7 & Kies3Setup.exe & $40 \mathrm{MB}$ & 9.5 & 15.6 \\
\hline 8 & Ultra edit.exe & $50 \mathrm{MB}$ & 10.2 & 19.7 \\
\hline 9 & opnt37.mp4 & $100 \mathrm{MB}$ & 11.9 & 22.7 \\
\hline 10 & HaikS224INDO.mkv & $110 \mathrm{MB}$ & 13.5 & 39.4 \\
\hline 11 & HaikS225.END.mp4 & $120 \mathrm{MB}$ & 16.7 & 46.5 \\
\hline 12 & HaikS222INDO.mp4 & $130 \mathrm{MB}$ & 18.5 & 63.4 \\
\hline 13 & $\begin{array}{l}\text { Naruto471.1080p. } \\
\text { mp4 }\end{array}$ & $140 \mathrm{MB}$ & 20.1 & 71.9 \\
\hline 14 & jdkwindowsx64.exe & $200 \mathrm{MB}$ & 22.0 & 95.3 \\
\hline 15 & BlueStacks2.exe & $250 \mathrm{MB}$ & 24.4 & 152.9 \\
\hline 16 & Memu-Setup.exe & $300 \mathrm{MB}$ & 28.9 & 219.7 \\
\hline 17 & $\begin{array}{l}\text { Central.Intel 480p. } \\
\text { mkv }\end{array}$ & $350 \mathrm{MB}$ & 30.1 & 273.0 \\
\hline 18 & $\begin{array}{l}\text { Wrong Turn 5.480p. } \\
\text { mkv }\end{array}$ & $400 \mathrm{MB}$ & 38.3 & 347.3 \\
\hline 19 & Deadpool.480p.mkv & $450 \mathrm{MB}$ & 40.8 & 366.0 \\
\hline 20 & ROM advan S4A.rar & $500 \mathrm{MB}$ & 49.4 & 380.4 \\
\hline 21 & $\begin{array}{l}\text { ROMSTOCK } \\
\text { R1001.rar }\end{array}$ & $550 \mathrm{MB}$ & 59.6 & 421.5 \\
\hline 22 & Counter strike.zip & $600 \mathrm{MB}$ & 61.4 & 450.9 \\
\hline 23 & $\begin{array}{l}\text { Deadpool.HDCAM. } \\
\text { mp4 }\end{array}$ & $650 \mathrm{MB}$ & 79.1 & 465.2 \\
\hline 24 & $\begin{array}{l}\text { Victor.Frank720p. } \\
\text { mkv }\end{array}$ & $700 \mathrm{MB}$ & 99.9 & 490.1 \\
\hline 25 & Counter strike v7.exe & $750 \mathrm{MB}$ & 105.1 & 515.9 \\
\hline 26 & CATIA-V5R16.zip & $800 \mathrm{MB}$ & 121.9 & 529.2 \\
\hline 27 & $\begin{array}{l}\text { RomRedmi3Unbrick. } \\
\text { zip }\end{array}$ & $850 \mathrm{MB}$ & 149.5 & 550.2 \\
\hline 28 & $\begin{array}{l}\text { miui_HM3_6.5- } \\
\text { 5.1.zip }\end{array}$ & $900 \mathrm{MB}$ & 160.2 & 583.2 \\
\hline 29 & Office2016.64.ISO & $950 \mathrm{MB}$ & 180.7 & 629.1 \\
\hline 30 & Spectre.2015.720p.rar & $1 \mathrm{~GB}$ & 210.5 & 685.4 \\
\hline
\end{tabular}

Pada Tabel 1 diujikan waktu upload dan download untuk file dengan kapasitas mulai dari 3MB sampai dengan $1 \mathrm{~GB}$, diperoleh rata-rata waktu download adalah 4 menit 54 detik. Sedangkan ratarata waktu upload adalah 9 menit 24 detik.

\subsubsection{Berdasarkan Kecepatan Transfer}

Selain waktu yang diperlukan jaringan untuk download dan upload file juga dilakukan pengujian terhadap transfer rate dari file tersebut.Tabel 2 merupakan hasil pengujian transfer rate untuk download dan upload.

Tabel 2. Data Pengujian Transfer Rate dengan LAN

\begin{tabular}{|c|c|c|c|c|}
\hline \multirow[t]{2}{*}{ No } & \multirow[t]{2}{*}{ Nama File } & \multirow{2}{*}{$\begin{array}{l}\text { Ukuran } \\
\text { File }\end{array}$} & \multicolumn{2}{|c|}{$\begin{array}{c}\text { Kecepatan } \\
\text { transfer rate } \\
(\mathrm{Kbps})\end{array}$} \\
\hline & & & $\begin{array}{c}\text { Down- } \\
\text { load }\end{array}$ & Upload \\
\hline 1 & Foto.jpg & $3 \mathrm{MB}$ & 1000 & 750 \\
\hline 2 & Mp3 & $4 \mathrm{MB}$ & 800 & 800 \\
\hline 3 & PDF & $5 \mathrm{MB}$ & 833 & 714 \\
\hline 4 & Word & $10 \mathrm{MB}$ & 1667 & 909 \\
\hline 5 & MiPhoneflash.exe & $20 \mathrm{MB}$ & 2857 & 1667 \\
\hline 6 & MiSetup2.exe & $30 \mathrm{MB}$ & 3333 & 2308 \\
\hline 7 & Kies3Setup.exe & $40 \mathrm{MB}$ & 4444 & 2857 \\
\hline 8 & Ultra edit.exe & $50 \mathrm{MB}$ & 5000 & 2941 \\
\hline 9 & opnt37.mp4 & $100 \mathrm{MB}$ & 8333 & 4167 \\
\hline 10 & HaikS224INDO.mkv & $110 \mathrm{MB}$ & 8462 & 3667 \\
\hline 11 & HaikS225.END.mp4 & $120 \mathrm{MB}$ & 7059 & 2609 \\
\hline 12 & HaikS222INDO.mp4 & $130 \mathrm{MB}$ & 7222 & 2167 \\
\hline 13 & $\begin{array}{l}\text { Naruto471.1080p. } \\
\text { mp4 }\end{array}$ & $140 \mathrm{MB}$ & 7000 & 1972 \\
\hline 14 & jdkwindowsx64.exe & $200 \mathrm{MB}$ & 9091 & 2439 \\
\hline 15 & BlueStacks2.exe & $250 \mathrm{MB}$ & 10417 & 2717 \\
\hline 16 & Memu-Setup.exe & $300 \mathrm{MB}$ & 10345 & 1685 \\
\hline 17 & Central.Intel 480p.mkv & $350 \mathrm{MB}$ & 11667 & 1944 \\
\hline 18 & $\begin{array}{l}\text { Wrong Turn 5.480p. } \\
\text { mkv }\end{array}$ & $400 \mathrm{MB}$ & 10526 & 1914 \\
\hline 19 & Deadpool.480p.mkv & $450 \mathrm{MB}$ & 10976 & 1304 \\
\hline 20 & ROM advan S4A.rar & $500 \mathrm{MB}$ & 10204 & 1412 \\
\hline 21 & $\begin{array}{l}\text { ROMSTOCK R1001. } \\
\text { rar }\end{array}$ & $550 \mathrm{MB}$ & 9167 & 1482 \\
\hline 22 & Counter strike.zip & $600 \mathrm{MB}$ & 9836 & 1504 \\
\hline 23 & $\begin{array}{l}\text { Deadpool.HDCAM. } \\
\text { mp4 }\end{array}$ & $650 \mathrm{MB}$ & 8228 & 1505 \\
\hline 24 & Victor.Frank720p.mkv & $700 \mathrm{MB}$ & 7000 & 1570 \\
\hline 25 & Counter strike v7.exe & $750 \mathrm{MB}$ & 6522 & 1599 \\
\hline 26 & CATIA-V5R16.zip & $800 \mathrm{MB}$ & 6557 & 1633 \\
\hline 27 & $\begin{array}{l}\text { RomRedmi3Unbrick. } \\
\text { zip }\end{array}$ & $850 \mathrm{MB}$ & 5705 & 1638 \\
\hline 28 & $\begin{array}{l}\text { miui_HM3_6.5- } \\
\text { 5.1.zip }\end{array}$ & $900 \mathrm{MB}$ & 5625 & 1664 \\
\hline 29 & Office2016.64.ISO & $950 \mathrm{MB}$ & 5249 & 1699 \\
\hline 30 & Spectre.2015.720p.rar & $1 \mathrm{~GB}$ & 4762 & 1637 \\
\hline
\end{tabular}


Pada Tabel 2 diujikan kecepatan transfer rate untuk download dan upload. Dari hasil pengujian diperoleh rata-rata kecepatan transfer rate untuk download adalah $4.762 \mathrm{Kbps}$ sedangkan rata-rata kecepatan transfer rate untuk upload adalah 1.896Kbps.

\subsubsection{Berdasarkan Jumlah Client}

Pada pengujian jumlah client dilakukan untuk melihat kinerja QoS (quality of service). QoS ini akan dilakukan pengujian pengiriman data memanfaatkan koneksi kabel LAN dengan menggunakan client sebanyak 20 PC.

1. Pengujian terhadap 5 PC client

Pada pengujian terhadap 5 PC client menggunakan file dengan ukuran 10MB. Pada pengujian ini client akan mengakses secara bersamaan file tersebut. Table 3 merupakan pengujian terhadap 5 PC client.

Tabel 3. 5 PC Client

\begin{tabular}{|c|c|c|c|c|}
\hline No PC & Jenis file & ukuran & $\begin{array}{c}\text { Keberhasilan } \\
(\mathbf{\%})\end{array}$ & status \\
\hline 1 & PDF & $10 \mathrm{MB}$ & $100 \%$ & Sukses \\
\hline 2 & PDF & $10 \mathrm{MB}$ & $100 \%$ & Sukses \\
\hline 3 & PDF & $10 \mathrm{MB}$ & $100 \%$ & Sukses \\
\hline 4 & PDF & $10 \mathrm{MB}$ & $100 \%$ & Sukses \\
\hline 5 & PDF & $10 \mathrm{MB}$ & $100 \%$ & Sukses \\
\hline 1 & PDF & $10 \mathrm{MB}$ & $100 \%$ & Sukses \\
\hline
\end{tabular}

Pada Tabel 3 rata-rata tingkat kesuksesan mencapai $100 \%$.

2. Pengujian terhadap $10 \mathrm{PC}$ client

Pada pengujian terhadap 10 PC client menggunakan file dengan ukuran 10MB. Pada pengujian ini client akan mengakses secara bersamaan file tersebut. Table 4 merupakan pengujian terhadap 10 PC client.

Tabel 4. 10 PC Client

\begin{tabular}{|c|c|c|c|c|}
\hline No pc & Jenis file & Besar file & $\begin{array}{c}\text { Keberhasilan } \\
(\mathbf{\%})\end{array}$ & Status \\
\hline 1 & PDF & $10 \mathrm{MB}$ & $100 \%$ & Sukses \\
\hline 2 & PDF & $10 \mathrm{MB}$ & $100 \%$ & Sukses \\
\hline 3 & PDF & $10 \mathrm{MB}$ & $100 \%$ & Sukses \\
\hline 4 & PDF & $10 \mathrm{MB}$ & $100 \%$ & Sukses \\
\hline 5 & PDF & $10 \mathrm{MB}$ & $100 \%$ & Sukses \\
\hline 6 & PDF & $10 \mathrm{MB}$ & $100 \%$ & Sukses \\
\hline 7 & PDF & $10 \mathrm{MB}$ & $100 \%$ & Sukses \\
\hline 8 & PDF & $10 \mathrm{MB}$ & $100 \%$ & Sukses \\
\hline 9 & PDF & $10 \mathrm{MB}$ & $70 \%$ & Gagal \\
\hline 10 & PDF & $10 \mathrm{MB}$ & $50 \%$ & Gagal \\
\hline
\end{tabular}

Pada pengujian terhadap 10 PC tingkat keberhasilan mencapai $92 \%$.

\section{Pengujian terhadap 15 PC client}

Pada pengujian terhadap 15 PC client menggunakan file dengan ukuran 10MB. Pada pengujian ini client akan mengakses secara bersamaan file tersebut. Table 5 merupakan pengujian terhadap 15 PC client.

Tabel 5. 15 C Client

\begin{tabular}{|c|c|c|c|c|}
\hline No PC & jenis file & besar file & $\begin{array}{c}\text { Keberhasilan } \\
\mathbf{( \% )}\end{array}$ & Status \\
\hline 1 & PDF & $10 \mathrm{MB}$ & $100 \%$ & Sukses \\
\hline 2 & PDF & $10 \mathrm{MB}$ & $89 \%$ & Gagal \\
\hline 3 & PDF & $10 \mathrm{MB}$ & $40 \%$ & Gagal \\
\hline 4 & PDF & $10 \mathrm{MB}$ & $100 \%$ & Sukses \\
\hline 5 & PDF & $10 \mathrm{MB}$ & $100 \%$ & Sukses \\
\hline 6 & PDF & $10 \mathrm{MB}$ & $100 \%$ & Sukses \\
\hline 7 & PDF & $10 \mathrm{MB}$ & $100 \%$ & Sukses \\
\hline 8 & PDF & $10 \mathrm{MB}$ & $100 \%$ & Sukses \\
\hline 9 & PDF & $10 \mathrm{MB}$ & $80 \%$ & Gagal \\
\hline 10 & PDF & $10 \mathrm{MB}$ & $50 \%$ & Gagal \\
\hline 11 & PDF & $10 \mathrm{MB}$ & $20 \%$ & Gagal \\
\hline 12 & PDF & $10 \mathrm{MB}$ & $100 \%$ & Sukses \\
\hline 13 & PDF & $10 \mathrm{MB}$ & $100 \%$ & Sukses \\
\hline 14 & PDF & $10 \mathrm{MB}$ & $10 \%$ & Gagal \\
\hline 15 & PDF & $10 \mathrm{MB}$ & $77 \%$ & Gagal \\
\hline
\end{tabular}

Pada pengujian terhadap 15 PC client tingkat keberhasilan semakin menurun yaitu $78 \%$, hal ini disebabkan mulai adanya bottleneck di dalam jaringan tersebut.

\section{Pengujian terhadap 20 PC client}

Pada pengujian terhadap 20 PC client menggunakan file dengan ukuran 10MB. Pada pengujian ini client akan mengakses secara bersamaan file tersebut. Table 6 merupakan pengujian terhadap $20 \mathrm{PC}$ client.

Tabel 6. 20 PC Client

\begin{tabular}{|c|c|c|c|c|}
\hline No PC & jenis file & besar file & $\begin{array}{c}\text { Keberhasilan } \\
\mathbf{( \% )}\end{array}$ & Status \\
\hline 1 & PDF & $10 \mathrm{MB}$ & $98 \%$ & Gagal \\
\hline 2 & PDF & $10 \mathrm{MB}$ & $49 \%$ & Gagal \\
\hline 3 & PDF & $10 \mathrm{MB}$ & $92 \%$ & Gagal \\
\hline 4 & PDF & $10 \mathrm{MB}$ & $100 \%$ & Sukses \\
\hline 5 & PDF & $10 \mathrm{MB}$ & $100 \%$ & Sukses \\
\hline 6 & PDF & $10 \mathrm{MB}$ & $72 \%$ & Gagal \\
\hline 7 & PDF & $10 \mathrm{MB}$ & $100 \%$ & Sukses \\
\hline
\end{tabular}


Lanjutan Tabel 6

\begin{tabular}{|c|c|c|c|c|}
\hline No PC & jenis file & besar file & $\begin{array}{c}\text { Keberhasilan } \\
(\mathbf{\%})\end{array}$ & Status \\
\hline 8 & PDF & $10 \mathrm{MB}$ & $86 \%$ & Gagal \\
\hline 9 & PDF & $10 \mathrm{MB}$ & $88 \%$ & Gagal \\
\hline 10 & PDF & $10 \mathrm{MB}$ & $69 \%$ & Gagal \\
\hline 11 & PDF & $10 \mathrm{MB}$ & $33 \%$ & Gagal \\
\hline 12 & PDF & $10 \mathrm{MB}$ & $100 \%$ & Sukses \\
\hline 13 & PDF & $10 \mathrm{MB}$ & $100 \%$ & Sukses \\
\hline 14 & PDF & $10 \mathrm{MB}$ & $71 \%$ & Gagal \\
\hline 15 & PDF & $10 \mathrm{MB}$ & $25 \%$ & Gagal \\
\hline 16 & PDF & $10 \mathrm{MB}$ & $100 \%$ & Sukses \\
\hline 17 & PDF & $10 \mathrm{MB}$ & $100 \%$ & Sukses \\
\hline 18 & PDF & $10 \mathrm{MB}$ & $11 \%$ & Gagal \\
\hline 19 & PDF & $10 \mathrm{MB}$ & $100 \%$ & Sukses \\
\hline 20 & PDF & $10 \mathrm{MB}$ & $100 \%$ & Sukses \\
\hline
\end{tabular}

Pada pengujian terhadap 20 PC client tingkat keberhasilan semakin menurun yaitu $80 \%$, hal ini disebabkan mulai adanya bottleneck di dalam jaringan tersebut.

\section{Kesimpulan}

1. Sistem akses file berbasis client server dengan menggunakan samba server berhasil di implementasikan.

2. Waktu yang dibutuhkan jaringan LAN pada sistem akses file berbasis client sever menggunakan samba server dengan ukuran file minimal 3MB dan maksimal $1 \mathrm{~GB}$ untuk proses download adalah 04 menit 54 detik sedangkan untuk upload adalah 09 menit 24 detik

3. Kecepatan transfer rate yang hasilkan dengan ukuran file minimal $3 \mathrm{MB}$ dan maksimal $1 \mathrm{~GB}$ untuk proses download adalah $4.762 \mathrm{Kbps}$ dan untuk upload adalah $1.896 \mathrm{Kbps}$.

4. Pada pengujian QoS dilakukan terhadap 5 PC, 10PC, 15PC dan 20PC client diperoleh hasil semakin banyak PC client yang mengakses 1 file tingkat keberhasilannya akan semakin buruk, hal ini disebabkan karena adanya bottleneck terhadap jaringan tersebut.

\section{Saran}

1. Kedepannya dapat dilakukan pengujian terhadap jaringan wireless.
2. Pada penelitin selanjutnya dapat diterapkan pada jaringan yang lebih luas.

3. Pada penelitian selanjutnya diharapkan memperhitungkan manajemen bandwidth untuk client

\section{Ucapan Terima Kasih}

Penulis mengucapkan terima kasih kepada Sekolah Tinggi Teknologi Adisutjipto Yogyakarta yang telah memberi dukungan financial terhadap penelitian ini.

\section{DAFTAR PUSTAKA}

[1] Isminaldi, 2009., Penerapan Sistem Samba Server Menggunakan Ubuntu 8.04 Di SMA Swasta Insani Binjai., Skripsi., Program Studi D-3 Ilmu Komputer, Fakultas Matematika dan Ilmu Pengetahuan Alam, Universitas Sumatra Utara, Medan.

[2] Fadli, F., 2012., Penerapan File Server Menggunakan Samba dan LDAP di U'Budiyah Indonesia., Skripsi., Program studi Teknik Informatika., Sekolah Tinggi Manajemen Informatika dan Komputer STMIK U’Budiyah Indonesia., Banda Aceh.

[3] Khairil., Riyanto N. P., Rosmeri., 2013., Membangun Webserver Intranet Dengan Linux (Studi Kasus di Laboratorium Komputer SMP N 38 Bengkulu Selatan), Jurnal Media Infotama, Vol. 9, No.1., ISSN : 1858-2680.

[4] Irawan, Budhi. 2007, Jaringan Komputer., Graha Ilmu ., Bandung.

[5] Sugiono D., 2013., Komunikasi data dan Internet., Kementrian Pendidikan dan Kebudayaan., Jakarta

[6] Khairil., Riyanto N P., Rosmeri., 2013., Membangun Webserver Internet dengan Linux ., Jurnal Media Infotama, Vol.9, No.1, ISSN: 1858 - 2680 